Western University

Scholarship@Western

$11-2008$

Referral in the Wake of Conscientious Objection to Abortion

Carolyn McLeod

The University of Western Ontario

Follow this and additional works at: https://ir.lib.uwo.ca/philosophypub

Part of the Bioethics and Medical Ethics Commons, Feminist, Gender, and Sexuality Studies Commons, and the Philosophy Commons

Citation of this paper:

McLeod, Carolyn, "Referral in the Wake of Conscientious Objection to Abortion" (2008). Philosophy Publications. 333.

https://ir.lib.uwo.ca/philosophypub/333 


\title{
Referral in the Wake of Conscientious Objection to Abortion
}

\author{
By Carolyn McLeod
}

Abstract: Currently, the preferred accommodation for conscientious objection to abortion in medicine is to allow the objector to refuse to accede to the patient's request so long as the objector refers the patient to a physician who performs abortions. The referral part of this arrangement is controversial, however. Pro-life advocates claim that referrals make objectors complicit in the performance of acts that they, the objectors, find morally offensive. I argue that the referral requirement is justifiable, although not in the way that people usually assume that it is.

One of the major battles currently being waged over abortion has to do with conscientious objection among physicians. The conflict has two main sides. On one side are prochoice people who think that physicians should offer women all needed abortion services. On the other side are pro-life people who hold that physicians who conscientiously object to these services should not have to provide them. In the spirit of compromise, pro-choice people have agreed to allow conscientious objectors to opt out of performing abortions so long as these objectors make referrals for abortions. This arrangement is common; but even so, many pro-life people are dissatisfied with it. For them, it amounts to a false compromise, since it makes prolife physicians complicit in the performance of acts that they find morally offensive. Hence, the battle rages on over conscientious objection, with many pro-life people opposing the referral requirement at every turn. For example, pro-life physicians often simply violate the requirement ${ }^{1}$ and pro-life activists try to enact legislation that eliminates it. ${ }^{2}$ 
My own view is that pro-choice people need to join the battle over physician referral with as much vigor as pro-life people have, because the pro-life side is winning, at least intellectually speaking. As I'll argue, the pro-life side is correct in claiming that referral is not a true compromise for many pro-life physicians. And this means that the grounds that pro-choice people offer for why both sides ought to endorse the referral requirement — that it is a true compromise for both — are no good. The pro-choice side must come up with a better argument for referral as a general requirement for all objectors, because so much is at stake with this requirement. Without it, there would be no guarantee that women would know where to go to get abortions. ${ }^{3}$ Furthermore, practitioners other than physicians, such as pharmacists, who are relatively new to the battle over conscientious objection, are fighting for some conscience protection for themselves; and if we want to ensure that they do not get protection for refusals to refer, we had better get clear on why referral is morally necessary.

In what follows, I suggest justificatory paths toward referral other than compromise, after showing why the path of compromise is blocked. In particular, I consider the path of consent, which follows an argument that goes roughly like this: perhaps objectors ought to make referrals because they have consented to do so by virtue of consenting to medical norms which themselves require referral. I show that this path is not successful either, however. For while it is true that medical norms require referral and that objectors have consented to them, their consent alone does not justify the referral requirement or justify imposing this requirement on them.

In the end, I claim that the only true justificatory path toward referral is a path that defends the moral permissibility of abortion. Let me be clear at the outset about two features of this argument. 1) It presumes but does not establish the moral permissibility of abortions. What it establishes instead is that an argument in favor of their permissibility is needed to justify the 
referral requirement. 2) The argument responds to a moral problem (What would it take to ground the referral requirement, morally speaking?), rather than to a legal or public policy problem (Dwyer 1997). ${ }^{4}$ It shows how to defend a moral position against refusals to refer for abortion, but not how to create law or public policy in this area. I do not presume that law or policy on referrals for abortion is beholden to a moral argument that establishes the moral permissibility of abortion. Rather, I acknowledge that there are resources within law and medical policy that would allow one to insist upon referrals. Thus, my argument is strictly a moral one. Nevertheless, it has implications for law and public policy, for it shows how one could morally ground any requirement that conscientious objectors make referrals for abortion.

My position in this paper is also relevant beyond the specific problem of refusals to refer for abortion to the more general problem of conscientious objection by health care providers. My view suggests that entering into debates about the moral permissibility of any established health care practice is necessary if we are to determine whether practitioners can morally object to that practice. The abortion case is not unique in this regard. I focus on it because it is paradigmatic of conscientious objection in health care and because it is a topic of extreme importance for women..$^{5}$

\section{Against Referral as a True Compromise}

The first argument I'll consider for why objectors ought to refer is that referral is a true compromise for them. There are various reasons one might give to support such a claim. And bioethicists have given some of these reasons. But my hunch is that none of them are good reasons.

To explain my suspicion, I need to describe certain facts about compromises. First of all: a compromise "more or less split[s] the difference between opposing positions" (Benjamin 1990, 
5). Second of all, the compromise position is one that we, who are compromising, deem to be "worse on its own merits than [our] initial position" (May 2005, 318). ${ }^{6}$ To illustrate these two points, consider me and my colleague Tim, who have opposing positions on who to invite to our department as a visiting speaker. Tim and I might compromise by deciding to invite someone who has some of the qualities that only Tim values in a speaker and some of the qualities that only I value. Here, we'd be "splitting the difference" and adopting a position on who to invite that each of us deems to be inferior, on its merits, to our original position.

Why compromise at all, however, if doing so involves supporting a position that, in our own opinion, is not the best position to have on a particular issue? The answer must be that the compromise position serves other values or interests that we possess. For example, it may be that I value harmony within my academic department and that I value it more than getting my way about who to invite as a speaker. For these reasons, I could compromise with Tim about the speaker. Notice that the compromise position is best overall—it is superior in our opinion, given other values that we hold and given the disagreement that we face. Absent this disagreement or these facts about our values, we would see the compromise position as inferior and we would not adopt it.

These points shed light on the meaning of a true compromise as opposed to a false one. A true compromise is a compromise that we have good reasons to make, given our whole system of values, while a false compromise is a compromise that we have no good reason to make, given that system. To illustrate, consider a new scenario involving me and Tim, in which I feel pressured to compromise with him for the sake of harmony in our department, but harmony with Tim, at least, is not something I value. (Perhaps, I don’t particularly like Tim.) In fact, I would 
rather jeopardize harmony in the department than compromise with Tim. In that case, the compromise would clearly be a false one for me.

So the question of whether referral for abortion could be a true compromise for conscientious objectors comes down to whether objectors have values that would give them good reasons to make such a compromise. Assuming that their pro-life values dictate that referral is inferior to no referral (because referral involves complicity—see Blustein 1993, 307-9), are there other values that we could assume most objectors hold that would make referral superior for them, all things considered?

One such value might be respect for the sincerity and intelligence of people with whom one reasonably disagrees. Many philosophers have said that respect of this sort can engender true compromises (May 2005, 321). In fact, Jeffrey Blustein claims that it can explain why referral ought to be a true compromise for practitioners who object to practices, such as abortion, that generate reasonable disagreement $(1993,310) .{ }^{7}$ According to Blustein, being respectful requires that the objector acknowledge that "there are other sincere and serious physicians who could do what the patient asks in good conscience," and that the objector ought therefore to refer the patient to them (310).

While this all sounds plausible enough, however, it is not clear to me (and to others, most notably Simon Cabulea May) that respect can generate true compromises (May 2005, 340-2). My respect for the sincerity or intelligence of people with whom I disagree might encourage me to accept their opinions and to revise my own in light of those opinions. But if that happens, then the occasion for compromise has been lost. Instead, I have engaged in what May calls "moral correction" rather than compromise. Respect is not obviously a reason for compromise - that is, for accepting a position that one deems to be inferior on its merits to other positions. Granted, 
respect could be a reason for compromise if it was impossible to show respect without compromising. But surely that's rarely if ever the case. I could hold that my own position is superior to those of other people and still show respect for those people, by, for example, taking their "arguments ... seriously and tak[ing] the time to respond to th[ose arguments] appropriately" (May 2005, 342).

Another value that might allow objectors to refer is that of epistemic humility. An objector might value being humble about how much he knows, particularly about issues that are morally complex. He also might recognize that abortion is such an issue. ${ }^{8}$ These facts about him could then prompt him to accept the referral requirement, on the grounds that there is some risk that he's wrong about abortion and that by refusing to refer, he would be causing serious harm.

But this explanation does not show why referral would be a true compromise either. It only explains why objectors (those who are humble) perhaps ought to be guided in their actions by views about abortion that are less risky, epistemically and morally, than views that they currently hold. In other words, perhaps they ought to scale back (i.e., correct) their opinions about abortion. Examining the moral complexity of an issue can give us such an opportunitythat is, an opportunity for moral correction. But it provides no opportunity for compromise, not unlike mutual respect (May 2005). Complexity coupled with humility can only cause us to doubt that our views are correct, and doubt alone is not a reason for compromise. Why would doubting that one's own view is correct cause one to accept another view that elicits more doubt than the first (because one perceives it as inferior to the first)?

So far, I've suggested that the values of respect and epistemic humility cannot explain why referral would be a true compromise for conscientious objectors; and in fact, these values rarely explain why anything would be a true compromise for anyone. ${ }^{9} \mathrm{I}$ haven 't suggested that 
objectors could never in good conscience make referrals for abortion and do so out of respect or humility. These values could encourage them to correct or scale back their opinions about abortion, as I've mentioned, which in turn could prompt them to make referrals. Given how firmly many of them hold on to their views about abortion, however, I assume it is unlikely that many of them will engage in moral correction of this sort.

Let me now consider values that could generate true compromises and that objectors could possess. One such value is that of securing the safety or well-being of patients. Bearing in mind that for most objectors the fetus is a second patient, an objector might assume that the value of preserving the well-being of patients is a reason for referring a woman who wants an abortion to a competent abortion provider, because otherwise, she might seek out an incompetent abortion provider or try to abort her self. And if she does that, then both patients (she and the fetus) will suffer.

But whether the safety of patients provides a good reason for a pro-life physician to refer depends on the likelihood that the pregnant woman would suffer serious harm if the physician did not refer her. It may be that the woman could get a safe abortion quite easily without assistance from this physician. In such circumstances (which are common in some geographical areas), the objector could legitimately reason that she ought not to refer: for according to her values, the near certainty that the fetus will die if she does refer outweighs the mere possibility that both the woman and fetus will die, or be maimed or hurt, if she doesn't refer.

In evaluating reasons that objectors might have for referral, it is important to keep in mind how objectors view the moral status of fetuses and the killing of fetuses. According to most objectors, fetuses are persons and have as much right to life as the women who gestate them. Thus, in the eyes of most objectors, abortions - at least those that do not occur in self-defense- 
are murder. The strength of these pro-life values suggests that not many other values could outweigh them and allow an objector to compromise about abortion. For example, consider the value of liberal neutrality proposed by Blustein for objectors working in public institutions. Blustein says that an objector could believe that, "it is not the business of public institutions in a liberal society such as mine to enforce specific, controversial moral or religious conceptions" $(1993,310)$. Rather, such institutions ought to remain neutral on contested moral issues. With this in mind, the objector could compromise about abortion, according to Blustein. But would the compromise be a true one? It would only be true if the objector's commitment to liberal neutrality was stronger than his commitment to prevent abortions. And that's unlikely. Most objectors would not even put abortion in the category of "contested moral issues" about which a liberal institution or government ought to be neutral. For again, abortion is murder in their view; and murder should never fall into that category.

I doubt, in fact, that there are any values that we could assume most objectors have that would reasonably allow them to compromise by giving referrals for abortion. To suggest then that referral is a true compromise for all concerned, and therefore that the battle over conscientious objection is over, is wrongheaded. It's not that referral couldn't be a true compromise for pro-choice people; it would be a true compromise for many of them insofar as it served their goal of ensuring that women who need abortions get access to them. But, unfortunately, there is no symmetrical argument for the other side: referral is not a true compromise for most pro-life people.

\section{Against Consent for Referral}


With the path of compromise blocked, where else can we turn to justify the referral requirement? Here's another path that is both popular and attractive: a physician's conscience $a s$ a physician should not preclude her from making referrals for abortion (or any referrals that the profession demands) because, presumably, she freely chose to enter the profession and freely chooses to stay in it, and in doing so, "agreed [or agrees] to practice medicine according to the norms of the profession" (Blustein 312). ${ }^{10}$ Blustein considers this line of argument and claims that it "is open to an obvious reply. Physicians who deny a duty to refer are saying, in effect, that they do not share the medical profession's prevailing conception of itself" $(1993,312)$. To my ears, however, this reply is not obvious, or is at least not obviously a good reply. It may be true that some physicians have a conception of medicine that differs from the prevailing one. But the point of the argument is that they have agreed to practice in accordance with the prevailing conception.

It's important to get clear on what this argument relies upon. Underlying it is a view about the proper scope of conscientious objection in medicine (hereafter "the View about Scope" or VAS): physicians cannot make conscientious objections in their practices that violate established norms of the profession. Central to VAS is the idea that conscientious objection is permissible only if the practice being objected to is not an established professional norm. ${ }^{11}$

VAS would reasonably account for why conscientious objectors ought to make referrals if, 1) it in fact supported the referral requirement, along with the absence of any requirement that objectors perform abortions, and 2) it was morally justified. It is to these questions that I'll now turn.

Let me begin with the question about whether VAS condones the arrangement of allowing objectors not to perform abortions but requiring that they make referrals for abortion. 
The answer is "yes," in North America at least, where there are no established medical norms saying that physicians have to perform abortions, but there are many norms suggesting that they have to refer for abortions.

Let me explain the point about referral first. Which are the norms that require conscientious objectors to make referrals? I think these norms include not abandoning patients, respecting their autonomy, honoring their trust, and being beneficent towards them. Arguably, in medicine, there is an ethic of not abandoning patients, which is sometimes cited as the source of the referral requirement (see, e.g., Blustein 1993, 312). But it seems to me that one could also get this requirement out of the duty of physicians to respect the autonomy of their patients. To be autonomous, patients need options that are authentic to them, and abortion is one such option for many women in unwanted pregnancies. Respecting the autonomy of these women would therefore involve making them aware of this option and how they can access it. In other words, it would involve referral. A third relevant norm is that physicians ought to honor the trust that patients place in them to act in their, the patients', best interests, and to interpret "best interests" not just from the provider's own perspective, but from the perspectives of the patient and of the profession as well. According to many patients and the profession, abortion should be an option for women in unwanted pregnancies. It follows that not referring can violate patient trust. A final norm that supports referral is that physicians should act in their patients' best interests, as defined above. The profession tends to interpret beneficence toward women in unwanted pregnancies in terms of women having access to abortions. ${ }^{12}$ According to the prevailing norm of beneficence therefore, as well as those of trust, patient autonomy, and not abandoning patients, physicians should refer patients for abortions..$^{13}$ 
While this conclusion about referral is uncontroversial for many parts of North America, I recognize that it is controversial for others. For example, according to the College of Physicians and Surgeons of New Brunswick and the law in some U.S. states (e.g., Michigan and Illinois ${ }^{14}$ ), physicians who conscientiously object to abortion are not obliged to make referrals.

Whether VAS supports the ability of physicians to refuse to perform abortions is more straightforward. The answer is "yes," because there is no medical norm in North America that says physicians must perform abortions upon request. To be sure, if a woman had nowhere else to turn to get an abortion, a physician could violate norms of beneficence, trust, or autonomy if he turned the patient away. But if that were not the case-if, that is, another physician was available to do the abortion - the first physician's refusal would be permissible.

So I'm prepared to agree that VAS condones the arrangement of allowing objections to performance but not to referral.

Now let me turn to the second question, namely whether VAS is morally justified. The worry is this: even if VAS is consistent with the above arrangement, it could still lack independent credibility as a theory about when conscientious objection in medicine is morally permissible.

Limiting conscientious objection in medicine to what does not violate established norms is appealing for a number of reasons. First, it helps to preserve the integrity of the profession. Second, it helps to maintain patient trust, since, as I've argued elsewhere, confusion about what norms someone will follow can seriously inhibit trust (McLeod 2002). Also, when what people medically require is crucial to their well-being, their trust can be shattered by conscientious objection. Third, the point about consent is worth repeating. Physicians have agreed to follow the norms of their profession, if only by accepting the privileges that go along with membership in 
the profession. They do not need to be physicians; surely, they could do other things with their lives.

But what if, in deciding to be physicians, their goal was to improve the profession from the inside out? While perhaps we would not value such behavior if it aimed to make the profession more loving toward the "unborn," we would value it if it targeted areas of medicine that we thought were simply corrupt. It seems that VAS would have us oppose such behavior; and that is the most serious objection to VAS: it is too conservative with respect to professional norms. The norms themselves might be corrupt. They might say — to give some stark examples"Promote racial purity" or "Preserve state authority by falsifying medical records of torture victims." " Shouldn't we allow physicians to object in their clinical practice to these sorts of norms, even if the norms are well-established?

I think this objection is serious. Indeed, I think it calls for an amendment to VAS. One type of amendment would simply add exceptions to VAS in an effort to deal with the possibility of corrupt norms. For example, one might insist that physicians ought not to make conscientious objections that violate established norms, except when the norms require them to lay hands on someone not for that person's benefit, but for the benefit of others. ${ }^{16}$ It seems reasonable to assume that policies about conscientious objection should protect people from being forced to lay hands on other people (e.g. by going into armed combat). The above amendment would also accommodate many of our intuitions about norms to which we think conscientious objection should occur in medicine, including discriminatory norms (e.g., sterilize welfare moms) and norms about torture. But unfortunately, it could not handle all of those intuitions, including ones that say physicians ought not to harm patients by omitting treatment for them: that is, by not laying hands on them. Being protected from having to lay hands will not help physicians who 
oppose corrupt norms that say don't lay hands (e.g., on lesbians who request infertility treatment). So this amendment won't work.

I'll be honest: I'm skeptical of any amendment to VAS that requires — with or without exception - that physicians adhere to established medical norms simply because those norms are established and medical. Variations of this sort on VAS will always be subject to the objection that the relevant norms could be corrupt and that physicians ought not to abide by corrupt norms. The possibility of corruption suggests that the mere fact a norm is established and medical does not mean that a practicing physician ought never to object to it. That is true even if, or though, the physician has consented to practice according to established norms.

\section{In Favor of Referral as an Objective Moral Requirement}

But there is a variation on VAS that I think would work; and it appeals to an objective assessment of medical norms. Here's how it would go: physicians cannot make conscientious objections in their practices that violate established norms of the profession that are morally justified. Call this "the Objectivity View about Scope" or OVAS. If OVAS were correct, and if established norms in favor of referral for abortion were morally justified, then objectors would be prohibited from refusing to refer patients for abortions.

Such an argument in favor of referral is importantly different from the arguments we've considered so far. Those arguments aimed to establish that objectors are personally obligated to

make referrals, for their own values or actions commit them to it. By contrast, this new argument says that objectors are impersonally (or objectively) obligated to make referrals; they are obligated whether they could accept that fact or not. I think that we have to give up on the idea that an obligation to refer would normally be personal, and we have to explain instead why it is 
always impersonal or objective. I'll start us out on this new path by giving some defense of OVAS and by indicating how I think we could use it to support the referral requirement.

OVAS implies that physicians can object to norms that are not morally justified. It's just that they can't object to norms that are morally justified. Such a view is compelling for a couple of reasons. First, it allows physicians to object to any corrupt medical norm. Second, it precludes physicians from objecting to norms that are in fact morally justified, such as norms in favor of respecting patient autonomy or norms against discrimination. While we may not all agree about certain norms that favor abortion access (e.g., norms against treating fetuses as persons), we tend to agree about other norms and would be appalled if the profession allowed individual physicians to object to them. Consider the extreme example of a physician who "is ethically opposed to providing pain medication because he believes that pain is a sign of a moral flaw and is therefore deserved" (Wicclair 2000, 216). OVAS is surely correct in suggesting that we should not tolerate such opposition.

But OVAS is not immune to criticism. Before applying this principle to the abortion case, I'll consider three important criticisms of it: 1) that OVAS tells an incomplete story about why certain objections do not deserve protection; 2) that it does not take seriously the freedom of conscience of physicians and consequently expects too much of physicians; and 3) that it is useless for dealing practically with objections that violate medical norms whose justification is unclear.

\section{Objection 1: An Incomplete Story}

First consider why OVAS might tell an incomplete story, in particular about why an objection to providing pain relief should not receive protection. OVAS prohibits this objection because it contravenes a norm that is morally justified ("one ought to try to relieve pain"). The 
concern is that the objection itself is unjustified. But isn't the objection problematic as well because it goes against the very core of medicine, which is a commitment to relieve physical and mental suffering? One might claim that preserving the core of medicine should matter (even if the core were somewhat corrupt), because losing it would undermine the whole profession and that's a bad thing. Similarly, one might insist that destroying the trustworthiness of the profession — by, for example, allowing physicians to refuse to provide pain relief—would be bad. Overall then, one might propose that a number of criteria (e.g., the integrity of the profession, the trustworthiness of it, and the justification of medical norms) are relevant for assessing conscientious objections in medicine. Justification is not the only important criterion. ${ }^{17}$

But here's my problem with this sort of argument: even if justification isn't the only important criterion, it's surely the most important criterion. The integrity of the profession is not worth much, in the long term at least, if the norms that hold the profession together are unjustified, as the norm against providing pain relief surely is. Similarly, the trustworthiness of the profession is worth little (if it can be said to exist at all) when professional norms are corrupt. So while I'm prepared to concede that justification is not the only criterion we ought to use for evaluating conscientious objections, and that therefore OVAS tells an incomplete story about the ethics of objecting, I do believe that OVAS tells the most important part of the story.

\section{Objection 2: Expecting Too Much}

But we have left out an important criterion for assessing objections, one that could take precedence over justification: namely the freedom of conscience of the physician. ${ }^{18}$ Surely this freedom is relevant to assessing whether a physician can make a conscientious objection. Moreover, this freedom is not normally restricted to adhering to norms that are morally justified. By restricting it in this way among physicians, OVAS wrongly implies that physicians ought to 
be willing to risk serious self-betrayal for the sake of being a physician, or so the objection goes. The proper response to this objection is to note that OVAS only expects this much of a physician whose conscience is misguided. For example, in following her conscience, the physician would have to fail to accept that pain is generally not a sign of moral weakness, or that an actual person's bodily autonomy is more important than a potential person's life when the two come in conflict during pregnancy. Surely in their practices, physicians ought not to be able to follow their consciences when the voice of their conscience misleads them. There is too much at stake for patients to allow wholesale freedom of conscience among physicians.

Further in support of this view is the idea that physicians have an obligation as professionals to be as objective as possible in their practices. They are required, when necessary, to exercise "professional distance," which functions in part to encourage objectivity. "[P]rofessional distance is selectively withholding expression of personal values in professional life" (Martin 2000, 84). The withholding is selective because personal values that do not conflict with justified professional norms do not need to be withheld and in fact ought to be expressed if doing so would benefit clients or patients. By contrast, personal values that are purely subjective or that lack objectivity ought to be withheld. This is what professional distance requires. And if we value such distance, then we could not possibly think that OVAS is too demanding. ${ }^{19}$

So far, I've accepted that the freedom of conscience of objectors is important, as are the integrity and trustworthiness of the profession; but I've also argued that none of these criteria are as important as justification. Notice that even if this last claim were false, we would still need to rely on justification to settle the question about whether objectors ought to refer; for the other criteria will not yield definitive answers to this question. Our discussion about consent and compromise revealed that established norms in medicine support referral for abortion, for 
example, but that the conscience of the objector is compromised by referral. So for the sake of the profession and its integrity and trustworthiness, we ought to prevent conscientious objections to referral, but for the sake of individual objectors and their freedom of conscience, we ought to allow these objections. What would and should break this tie is an argument concluding that norms in favor of abortion access are morally justified.

\section{Objection 3: It can be Useless}

Before applying OVAS to the case of physicians who refuse to make referrals for abortion, I'll consider briefly the additional criticism of this principle that it is useless for public policy, particularly policy on issues that are morally complex and that breed substantial confusion about which norms are morally justified. Implicit in this objection is the thought that OVAS might be a principle of public policy; but it is not. OVAS is a moral principle, devised to help us deal with a moral problem, not a public policy problem. (It would be strange if OVAS were a principle of public policy, for such principles are too practical to make appeal to what's morally justified.) Still, OVAS and accompanying arguments about which norms are morally justified could ground public policies about conscientious objection. These moral considerations could under gird a policy stating objectors cannot refuse to refer for abortions.

But OVAS is only useful in the above way if the accompanying moral arguments exist (i.e., arguments showing that the relevant norms are morally justified). Some would argue that we do not and cannot have such arguments for norms that support abortions, because the abortion issue is simply irresolvable. Obviously I disagree. I think this issue is resolvable if we take seriously the rights and well-being of women in unwanted pregnancies and do not focus all of our attention on fetuses. I won't defend this position here ${ }^{20}$; but I will point out that one must 
defend something like it to be morally justified in supporting any access to abortions whatsoever, not just access obtained through referrals.

In summary, OVAS can be useful for public policy, even though it is not a principle intended for public policy, because it is a key feature of moral arguments that will support policies about conscientious objection that demand compliance with certain medical norms. Among these arguments are those that limit how much physicians can conscientiously object to abortion services.

Let me step back and recapitulate. I take myself to have shown two things: first that criticism of OVAS is not persuasive; and second that there are good reasons to endorse OVAS. I now need to say more about what OVAS implies about physicians who refuse to make referrals for abortion. In short, OVAS says that the refusals cannot violate justified medical norms. We know already that the refusals contravene norms about not abandoning patients, respecting their autonomy, honoring their trust, and being beneficent toward them. In "Against Consent," I interpreted these norms in such a way that they require access to abortions for women in unwanted pregnancies. One would have to show that these norms so interpreted are morally justified in order to prove using OVAS that physicians cannot refuse to refer patients for abortions. Of course, the above norms so interpreted are only morally justified if abortion itself is morally permissible. Thus, whether objectors can refuse to make referrals for abortion ultimately depends on whether abortions are morally permissible. Just so we're clear: that is my thesis. ${ }^{21}$

Once we have shown that abortions are in fact morally permissible, why we would then allow objectors to refer, rather than require them to perform abortions? The main reason concerns the well-being of patients. Simply put, it is better for patients to have physicians who can perform abortions with as little professional distance as possible, given how emotionally 
trying abortions can be for patients. Withholding the expression of personal values can be difficult, and patients who seek abortions should not have to be subjected to the expression of pro-life values.

Notice that if what grounds the referral requirement is patient welfare, then in environments where a referral is not possible, because there is no one to refer to, and where the objector could perform the abortion, he must perform it. The reason why is that patients who want or need abortions are generally better off getting an abortion from a conscientious objector than not getting an abortion at all. My approach to the issue of referral provides an answer, therefore, to a common objection that pro-choice people raise to the referral requirement: referrals are not possible in many rural environments. On my approach, whenever referral is not possible, performance is required.

While I think patient welfare is the strongest reason we can give for why objectors could refer even if abortion was morally permissible, I don't think it is the only reason we can give. Another concerns the well-being of objectors: psychologically, it may be easier for them to maintain professional distance with respect to referral as compared with performance, even if they think that the two are both morally wrong, because referral does not require them to engage in the bloody act of killing a fetus. They might have an especially strong objection to their agency being used directly in what they take to be an immoral (if not heinous) act, which could explain the psychological benefit to them of being able to refer. A further reason to allow referrals rather than demand performance is that this arrangement could be a symbol of the moral controversy surrounding abortion. While the arguments against abortion are not as persuasive as arguments in favor of it, the arguments against abortion are not incoherent. They are certainly 
not all in the same league as arguments in favor of racism, for example. So perhaps it is worth signaling that abortion is morally controversial, which is what we do by allowing referrals.

Thus, it is reasonable to assume that the referral requirement could be grounded in the moral permissibility of abortion. But more to the point, it would have to be grounded in that fact, for two important reasons. One is that alternative grounds for the requirement are inadequate: referral is not a true compromise for most objectors and consent to practice in accordance with medical norms does not generate a duty to refer (at least not one that is absolute). The other is that even if the justification of medical norms isn't the only criterion for assessing conscientious objection, it remains the most important criterion and the only one that can determine conclusively whether objectors ought to refer. So to make a long story short, medical norms that favor abortion access would have to be justified in order for the profession or the state to be justified in withholding conscience protection from physicians who oppose referrals.

But let me say one last thing. This paper shows how one ought to defend the referral requirement and is therefore a call to action to all those who would defend it. They, or we, need to be able to explain clearly why abortion is morally permissible and why the well-being of women depends upon the availability of abortions. Strong forces in society are trying to dismantle the referral requirement. But, as I've shown, we cannot rationally oppose these forces without confronting the abortion issue head on and supporting every woman's right to abortion.

\section{Endnotes}

This paper is central to the research project I had as a Faculty Fellow in the Comparative Program on Health and Society at the Munk Centre for International Studies, University of Toronto. I am grateful to the Lupina Foundation for its generosity in funding this fellowship. I 
am also grateful to various individuals and to various audiences for their feedback on the paper. The individuals include Andrew Botterell, Susan Sherwin, Françoise Baylis, and my colleagues in moral and political philosophy at the University of Western Ontario. The audiences include participants in the 2005 conferences of Feminist Ethics and Social Theory and of the Canadian Society for Women in Philosophy, and attendees at colloquia at the University of Toronto, Waterloo University, and Carleton University.

${ }^{1}$ Routine violations in Canada were a finding of a study done by the Canadian Abortion Rights Action League, or CARAL (2003). I imagine that such violations occur in the United States even more than in Canada, since opposition to abortion is stronger there than in Canada.

${ }^{2}$ And they are sometimes successful. I give examples below.

${ }^{3}$ One might have a preference for publicity over referral, meaning that rather than have objectors make referrals, one thinks they ought to be able to publicize their objections in their waiting rooms to prevent patients from making the requests that they, the objectors, find offensive. The problem with this solution, however, is that it does not guarantee that the women who enter these waiting rooms and who want abortions will know where to go to get them. Also, prospective patients who have no need for abortion services may conscientiously object to the content on the signs and feel that they cannot attend the relevant clinic, even though they have few other options for health care (Rebecca Kukla, personal communication).

${ }^{4}$ While legal and public policy problems can be solved by appeal to the law or to public policy (respectively), moral problems can be solved only by appeal to moral argument. 
${ }^{5}$ Abortion is perhaps the paradigm case of conscientious objection in medicine, and indeed is responsible for sparking the movement in favor of having conscience protection laws in the United States (Wicclair 2000, 207).

Since my focus is abortion, for simplicity of terminology, I will often talk of conscientious objectors, leaving it understood that the objectors I have in mind are physicians who object to abortion.

${ }^{6}$ The reason for that is simple: if we thought that the compromise position was as valuable as, or more valuable than, our initial position, then our actual position would be the compromise one. But then the compromise would not split the difference between our actual position and that of the person with whom we're compromising.

${ }^{7}$ Similarly, Benjamin suggests that these objectors ought to compromise out of mutual respect $(1990,36)$.

${ }^{8}$ Some bioethicists (e.g., Benjamin 1990, 164) offer moral complexity, coupled with humility, as a reason for why objectors ought to compromise about abortion.

${ }^{9}$ Implicit in my discussion of respect and humility is the idea that one could refuse to compromise and still be respectful or humble, that is, perhaps, unless someone gives one good reason to revise one's views. Such an idea is favorable not only to conscientious objectors, but also to those who would oppose them, including many feminists. Pro-choice feminists who refuse to compromise with objectors about abortion, who insist that objectors not hinder access to abortions for women, can consistently adopt such a stance and be respectful or humble (i.e., perhaps, unless objectors give these feminists good reason to change their pro-choice views). A path of compromise that follows the avenues of respect and humility, and suggests along the way 
that a refusal to compromise reveals a lack of respect or humility, is not a path that's particularly friendly to feminists.

10 This argument is an instance of a broader explanation for referral, which insists that in becoming physicians, objectors conceded something, namely their power always to let their individual conscience guide their actions. A further instance of this explanation is the following: physicians are, and have agreed to be, "operators of the public accommodation" of health care (Anderson 2005). As such, they must serve the public and do what the public wants. (One would then have to show that what the public wants are referrals for abortion.) This argument is open to an objection that is similar to the one I raise below to the argument that focuses on consent: the public might be corrupt, just as the norms might be (i.e., the norms to which physicians have consented).

${ }^{11}$ Notice too that the VAS restricts conscientious objection only within clinical practice; it does not prohibit physicians from rallying for change in other contexts, including those in which the real debate about medical norms takes place (e.g., professional meetings). What is an appropriate form of conscientious objection in those other contexts is different from what is appropriate in clinical practice, for reasons that will become clearer below.

${ }^{12}$ It does so, in all likelihood, because of its history of dealing with the horror of botched abortions when abortions were inaccessible.

${ }^{13}$ One might wonder where these norms come from. How can we be certain that the prevailing norm of beneficence, for example, is as I've described it? I assume that we can refer, in part, to the codes and statements of medical associations. For example, many associations of gynecologists and obstetricians endorse the FIGO (International Federation of Gynecologists and Obstetricians) document on "Professional and Ethical Responsibilities Concerning Sexual and 
Reproductive Rights," which acknowledges a "human right to freely choose if and when to have children." (See

http://www.sogc.org/iwhp/pdf/FIGOCODEOFHUMANRIGHTSBASEDETHICS.pdf) This right suggests that beneficence would demand referrals for (if not the performance of) abortions. The FIGO document also supports the interpretations I've given of autonomy and trust. Moreover, it says explicitly that conscientious objectors must make referrals.

A further source for norms would be actual medical practice and the norms that prevail within it. And there's also the law and how it governs the medical profession. For example, North American fiduciary laws and laws about disclosure surrounding informed consent, respectively, support my interpretations of the norms of autonomy and trust.

${ }^{14}$ See Michigan's “Conscientious Objector Policy Act” and Illinois's “Health Care Right of Conscience Act," found on websites for the legislatures of those states.

15 The first was a norm of Nazi medicine (Bachrach 2004). And the second may have been the norm for military medical personnel at Abu Ghraib and also for the physicians involved in "the Steve Biko affair." Some of the former physicians falsified death certificates of tortured Iraqi prisoners (Miles 2004). And the latter falsified medical certificates about Biko's condition (McLean and Jenkins 2003).

16 The exception here comes from a principle that Judith Jarvis Thomson defends in "A Defense of Abortion": she says that "one has a right to refuse to lay hands on people, even where it would be just and fair to do so, even where justice seems to require that somebody do so" $(1971,54)$. Justice or fairness are the relevant norms because Thomson is referring to situations in which someone has to lay hands on another out of fairness to someone else (e.g. lay hands on Jones, who has taken Smith's coat, and return the coat to Smith). Similarly, perhaps, where "justice," as 
defined by prevailing norms of medicine, says that physicians must do harm to patients for others' sakes, physicians can refuse to do so.

${ }^{17}$ Wicclair defends something like this view $(2000,224)$. But he fails to acknowledge that among the criteria used to assess objections, justification is the most important, as I argue it is below.

${ }^{18}$ Similarly, Wicclair considers the integrity of objectors. He says the impact on their integrity is relevant to determining whether we ought to take seriously the objections they make $(2000,221$ 2, 224-5).

${ }^{19}$ Bringing in professional distance also allows us to explain the intuition that objectors who refuse to provide referrals for abortion are being "unprofessional." They are letting their personal values to influence their professional judgment too much. In other words, they are not exercising proper professional distance.

${ }^{20}$ Others have already done a good job of defending it. See, for example, Addelson 1991, Jaggar forthcoming and 1997, Little 2005 and 1999, Mackenzie 1992, Purdy 1996, Sherwin 1992, and Thomson 1971.

${ }^{21}$ There is one exception to my thesis that I am willing to grant. The exception concerns cases in which the objector's refusal to refer violates a medical norm that does not presume the moral permissibility of abortion. I have a specific norm in mind: one that concerns evidence in medicine and says that physicians ought to have good or at least decent evidence to back up medical claims that they make in their practices. Physicians who refuse to refer for abortion because they believe that abortion harms women—psychologically, physically, or spirituallydo not respect this norm; and the reason why is that no credible evidence exists to support such a view about abortion. One can oppose these refusals to refer using OVAS without proving that 
abortion is morally permissible. One simply has to prove that these objectors lack sufficient evidence to back up their empirical claims about women and abortion.

\section{References}

Addelson, Kathryn Pyne. 1991. Impure thoughts: Essays on philosophy, feminism, and ethics. Philadelphia: Temple University Press.

Anderson, Elizabeth. 2005. So you want to live in a free society? (5): Common property, common carriers, and the case of the conscientious objecting pharmacist." Left2Right, August 2, http://left2right.typepad.com/main/2005/08/so_you_want to_.html

Bachrach, Susan. 2004. In the name of public health—Nazi racial hygiene. New england journal of medicine 351: 417-420.

Benjamin, Martin. 1990. Splitting the difference: Compromise and integrity in ethics and politics. Lawrence, KA: University of Kansas Press.

Blustein, Jeffrey. 1993. Doing what the patient orders: Maintaining integrity in the doctor-patient relationship. Bioethics 7 (4): 289-314.

CARAL (Canadian Abortion Rights Action League, now Canadians for Choice or CFC). 2003.

Protecting abortion rights in Canada. Available through CFC at

http://www.canadiansforchoice.ca/cfcresources.html

Dwyer, Susan. 1997. Understanding the problem of abortion. In The problem of abortion, ed.

Dwyer and Joel Feinberg, $3^{\text {rd }}$ ed. Belmont: Wadsworth.

Jaggar, Alison M. forthcoming. Abortion rights and gender justice worldwide. In Abortion:

Three Perspectives, by Phillip Devine, Alison Jaggar, Michael Tooley, and Celia Wolf-Devine. New York: Oxford. 
---. 1997. Regendering the U.S. abortion debate. Journal of Social Philosophy 28: 127-40.

Little, Margaret Olivia. 2005. The moral permissibility of abortion. In Contemporary debates in applied ethics, ed. Andrew Cohen. Malden: Blackwell.

---. 1999. Abortion, intimacy, and the duty to gestate. Ethical theory and moral practice 2: 295312.

Mackenzie, Catriona. 1992. Abortion and embodiment. Australasian journal of philosophy 70 (2): 136-155.

Martin, Mike W. 2000. Meaningful work: rethinking professional ethics. New York: Oxford University Press.

May, Simon Cabulea. 2005. Principled compromise and the abortion controversy. Philosophy and Public Affairs 33 (4): 317-348.

McLean, GR and Trefor Jenkins. 2003. The Steve Biko affair: A case study in medical ethics. Developing world bioethics 3 (1): 77-95.

McLeod, Carolyn. 2002. Self-trust and reproductive autonomy. Cambridge: MIT Press.

Miles, Steven H. 2004. Abu Ghraib: Its legacy for military medicine. Lancet 364: 725-729.

Purdy, Laura. 1996. Reproducing persons: issues in feminist bioethics. Ithaca: Cornell University

Press.

Sherwin, Susan. 1992. No longer patient: Feminist ethics and health care. Philadelphia: Temple University Press.

Thomson, Judith Jarvis. 1971. A defense of abortion. Philosophy and public affairs 1 (1): 47-66. Wicclair, Mark. 2000. Conscientious objection in medicine. Bioethics 14 (3): 205-227. 